\title{
Desain dan Manufaktur Mesin CNC Plasma 3 Sumbu PT. Bangun Mesin Sejahtera
}

\author{
Achmad Zaki Rahman ${ }^{1, a)}$, Teguh Sentiko Prabowo ${ }^{2, b)}$, Putu Mahayana Santika ${ }^{3, c)}$
}

\author{
${ }^{1}$ Balai Teknologi Mesin Perkakas, Produksi, dan Otomasi (BT-MEPPO) - BPPT \\ Gedung Teknologi 2 No. 251, Kawasan Puspiptek, Serpong, Tangerang Selatan-Banten, Indonesia, 15314
}

${ }^{2,3}$ Program Studi Teknik Mesin ITI,

Jl. Raya Puspiptek Serpong, Tangerang Selatan-Banten, Indonesia, 15320

a) achmad.zaki@bppt.go.id (corresponding author), b) teguhsentikoprabowo@gmail.com, ${ }^{\mathrm{c})}$ putumsantika@yahoo.com

\begin{abstract}
Abstrak
Pemotongan plasma otomatis adalah proses yang efektif untuk memotong logam dua dimensi yang kompleks dalam waktu singkat. Pengadaan mesin CNC plasma untuk pelaku UMKM pada bidang industri pengolahan pemotongan logam masih tergolong sulit dikarenakan harga yang mahal. Aplikasi DFMA diterapkan dalam menentukan keputusan desain rangka mesin. Desain rangka mesin yang dipilih adalah profil baja dengan material JIS G3466 SKTR490 $75 \mathrm{~mm} \mathrm{x}$ $75 \mathrm{~mm}$ x $2 \mathrm{~mm}$ dengan tegangan ijin $\sigma \mathrm{i}=162,5 \mathrm{MPa}$, sedangkan tegangan bending masksimum $\sigma \mathrm{b}=132,83 \mathrm{MPa}$. Selisih hasil analisis perhitungan manual dengan simulasi ANSYS untuk tegangan bending masksimum dan faktor keamanan adalah 0,75MPa dan 0,018. Proses manufaktur yang telah selesai dilakukan menghasilkan mesin CNC plasma yang sesuai standar.
\end{abstract}

Kata kunci: $C N C$, desain, manufaktur, pemotongan, plasma

\begin{abstract}
Automatic plasma cutting is an effective process for cutting complex two-dimensional metal in no time. The procurement of CNC plasma machines for MSMEs in the industry of cutting metal processing is still quite difficult due to the high price. The DFMA is applied in determining frame machine design decision. The selected machine frame design is steel profile with JIS G3466 SKTR490 75mm x 75mm $x$ 2mm material with allowable stress $\left(\sigma_{i}\right)=162,5 \mathrm{Mpa}$, while bending stress masksimum $\left(\sigma_{b}\right)=132,83 \mathrm{Mpa}$. The difference between manual calculation with the simulation of ANSYS for maximum bending stress and safety factor is 0,75Mpa and 0,018. The finished manufacturing process produces a standard CNC plasma machine.
\end{abstract}

Keywords: cutting, CNC, design, manufacture, plasma

\section{PENDAHULUAN}

Karena kebutuhan yang berkembang untuk pembuatan bagian logam fungsional, proses manufaktur yang cepat telah menjadi fokus penelitian dan pengembangan lebih lanjut [1]. Pada tahun 2012, jumlah pengusaha di Indonesia sebanyak 56.539.560 unit. Dari jumlah tersebut, Usaha Mikro Kecil dan Menengah (UMKM) sebanyak 56.534.592 unit atau 99.99\%. Sektor industri pengolahan berada di peringkat ke empat dengan presentase $6,41 \%$ dari seluruh sektor yang ada. ( LPPI dan Bank Indonesia, 2015 ) [2].

Proses pemotongan logam yang dapat diandalkan dalam kecepatan dan tingkat presisi yang baik adalah dengan menggunakan plasma cutting. Permasalahan dari plasma cutting yang umum digunakan di pasaran saat ini yaitu masih handy portable, serta tidak dilengkapi peralatan penggerak [3]. Mesin berbasis Computerized Numerical Control ( CNC ) yang dipadukan dengan plasma cutting dapat dijadikan solusi dari penunjang sistem pemotongan logam.
Permasalahan lainnya dari mesin CNC plasma buatan dalam negeri pada umumnya adalah standardisasi rangka mesin yang belum banyak terpenuhi. Standardisasi juga mengharuskan untuk menekan biaya produksi pengerjaan mesin yang seminimal mungkin. Selain itu, desain konstruksi meja pendukung benda kerja yang efektif adalah masalah penting untuk memastikan karir operasional mesin dalam jangka waktu panjang [4].

Pada perancangan rangka mesin CNC plasma banyak digunakan jenis material aluminium dan baja. Dalam peneletian ini digunakan material profil baja dengan standar minimal tegangan yang diijinkan sebesar $150 \mathrm{Mpa}$ dengan faktor keamanan sebesar 2 yang mengacu pada beban statis yang bekerja pada rangka mesin.

\section{LANDASAN TEORI}

\section{A. CNC Plasma cutting}

Plasma adalah suatu bentuk fase zat ke-4 setelah fase padat, cair, dan gas. Jika ditambahkan kalor, es akan berubah wujud dari padat ke cair, dan jika diberikan kalor 
berlebih maka zat cair tersebut akan berubah menjadi uap. Jika uap tersebut ditambahkan kalor lagi maka akan berubah menjadi wujud plasma [5]. Tegangan listrik yang tinggi diperlukan untuk memberikan gaya pada elektronelektron arus listrik untuk dapat melalui jenis logam yang berhambatan tinggi tersebut, dimana akibat dari penambahan tegangan listrik tersebut, logam tersebut menjadi panas.

Sumber daya yang diperlukan untuk proses plasma cutting harus memiliki tegangan tinggi. Walaupun tegangan operasi untuk mempertahankan plasma biasanya $50 \mathrm{~V}$ sampai $60 \mathrm{~V}$ tetapi tegangan awal yang dibutuhkan bisa mencapai 400V DC [6]. Proses pemotongan dengan plasma secara skematis ditunjukkan pada Gambar 1.

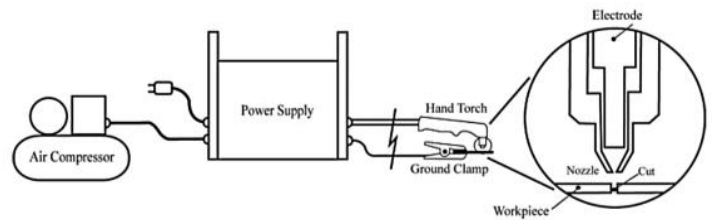

Gambar 1. Proses Pemotongan pada Mesin Plasma Cutting

\section{B. Design For Manufacture and Assembly ( DFMA)}

Kita akan mengasumsikan bahwa "untuk memproduksi" mengacu pada pembuatan bagian-bagian komponen individu dari suatu produk atau perakitan dan "untuk merakit" mengacu pada penambahan atau penggabungan bagian-bagian untuk membentuk produk yang telah selesai. Oleh karena itu, istilah "Design For Manufacture" (atau DFM) berarti desain untuk kemudahan pembuatan koleksi bagian-bagian yang membentuk produk setelah perakitan dan "Design For Manufacture and Assembly" (atau DFA) berarti desain produk untuk kemudahan perakitan. Design For Manufacture and Assembly (DFMA) adalah kombinasi dari DFA dan DFM [7].

\section{Distribusi Beban dan Tegangan pada Rangka Mesin}

Tata letak beban dari desain rangka mesin mempunyai peranan penting dalam menentukan kekuatan rangka. Skema gaya - gaya pada sebuah batang sederhana dapat dilihat pada Gambar 2 berikut:

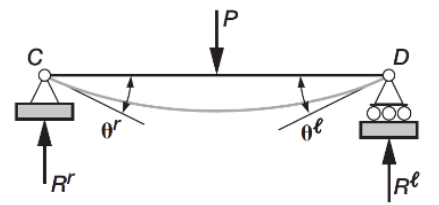

Gambar 2. Skema Gaya pada Batang Sederhana

Guna menentukan gaya-gaya reaksi yang terjadi pada tumpuan, pada mulanya digunakan persamaan (1) dengan prinsip statika struktur [8].

$$
\sum F_{y}=0
$$

Dari gaya reaksi yang telah diketahui, dapat ditentukan besarnya momen bending. Untuk menghitung besarnya momen bending dari skema diatas, digunakan persamaan (2): $\sum M_{i}=0 ; \quad M R-R x+M(x)=0$

Tegangan bending yang terjadi pada rangka dapat ditentukan dengan persamaan (3):

$\sigma_{b}=\frac{M_{\max }}{W}$

Tegangan bending yang terjadi tidak boleh lebih besar dari tegangan ijin pada material. Oleh karena itu, dengan memasukkan analogi tersebut didapatkan persamaan (4) dan (5):

$\sigma_{i}=\frac{\sigma_{y}}{s f}$

$\sigma_{i}>\sigma_{b}$

\section{Metode Elemen Hingga}

ANSYS adalah program komputer elemen dengan tujuan umum yang komprehensif, berisi lebih dari 100.000 baris kode. ANSYS mampu melakukan pemindahan statis, dinamis, perpindahan panas, aliran fluida, dan elektromagnetisme. ANSYS telah menjadi program FEA terdepan selama lebih dari 20 tahun. ANSYS digunakan di banyak bidang teknik, termasuk kedirgantaraan, otomotif, elektronik, dan nuklir. Untuk menggunakan ANSYS atau program komputer FEA "akar" lainnya dengan cerdas, sangat penting bahwa seseorang pertama-tama memahami konsep dasar dan keterbatasan metode elemen hingga yang mendasarinya. ANSYS adalah alat teknik yang sangat kuat dan mengesankan yang dapat digunakan untuk memecahkan berbagai masalah [9].

\section{METODE PENELITIAN}

Dalam melakukan penelitian, dibuatkan diagram alir untuk mempermudah memahami alur penelitian dari awal sampai dengan akhir. Diagram alir penelitian ditunjukkan pada Gambar 3. 


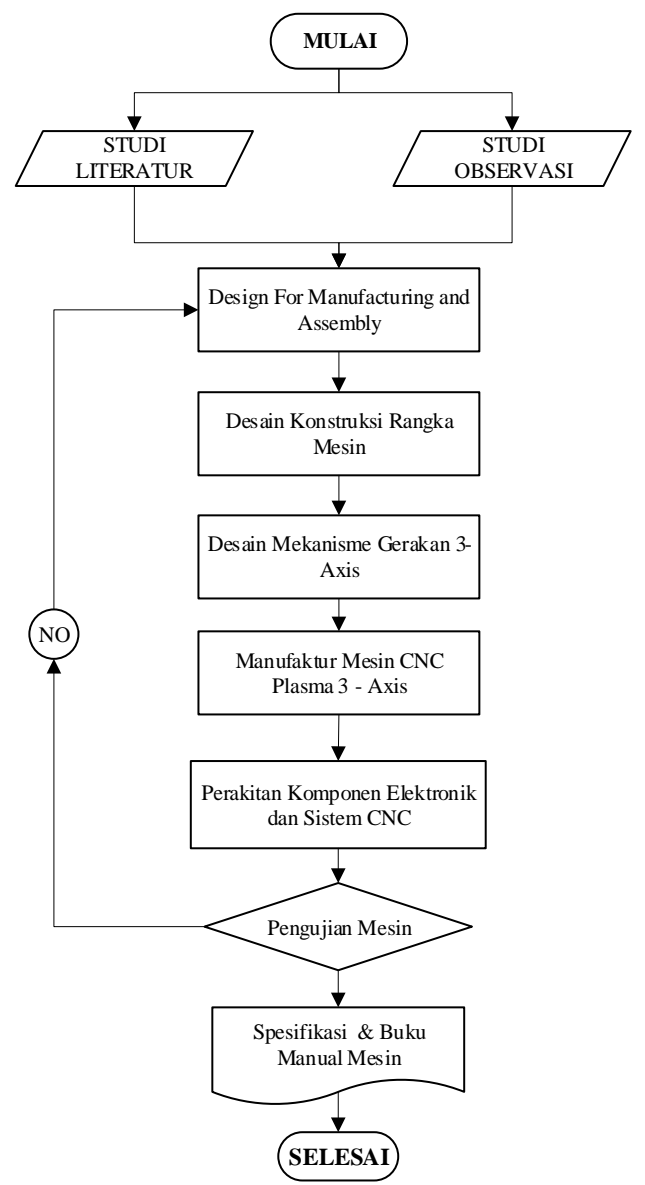

Gambar 3. Diagram Alir Penelitian

\section{HASIL DAN PEMBAHASAN}

\section{A. Hasil Analisis DFMA}

Pengambilan keputusan desain konstruksi mesin dilakukan dengan menggunakan metode DFMA. Desain perakitan original mesin CNC berasal dari BT-MEPPO. Desain perakitan mesin tersebut diterangkan pada Gambar 4.

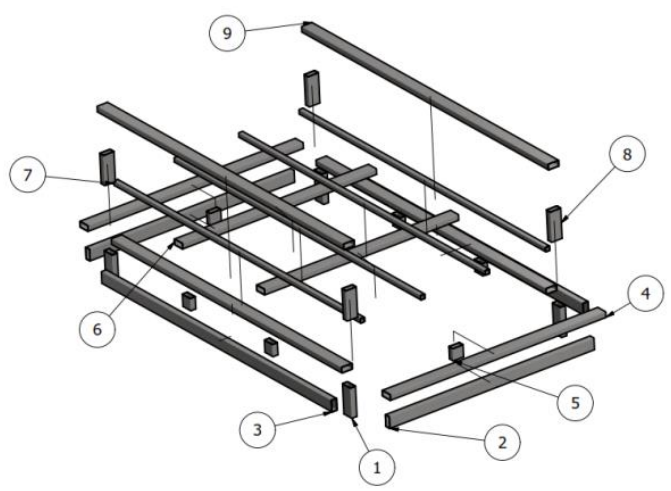

Gambar 4. Desain Perakitan Original Rangka CNC Plasma

Analisis index perakitan desain original mesin CNC yang dibuat di BT-MEPPO dijelaskan pada Tabel 1 Berikut.
Tabel 1. Analisis index perakitan desain rangka orisinil

\begin{tabular}{clcc}
\hline No & \multicolumn{1}{c}{ Deskripsi } & $\begin{array}{c}\text { Elemen } \\
\text { terhitung }\end{array}$ & Waktu perakitan ( s ) \\
\hline 1 & Kaki Rangka & 4 & 400 \\
2 & Penghubung bawah & 2 & 400 \\
3 & Penghubung sisi & 2 & 400 \\
4 & Dasar depan & 2 & 400 \\
5 & Penyangga meja & 6 & 400 \\
6 & Tumpuan meja & 2 & 400 \\
7 & Tumpuan meja kecil & 4 & 1600 \\
8 & Tiang gantry & 4 & 400 \\
9 & Gantry & 4 & 400 \\
\hline \multicolumn{4}{c}{ TOTAL } \\
\multicolumn{4}{c}{ Index Perakitan : $\frac{30 \times 400}{4800}=2,5 \%$} \\
\hline
\end{tabular}

Dari desain mesin acuan dibuatkan desain ulang yang memodifikasi beberapa bagian yang tidak diperlukan serta kemudahan dalam perakitan yang ditunjukkan pada Gambar 5.

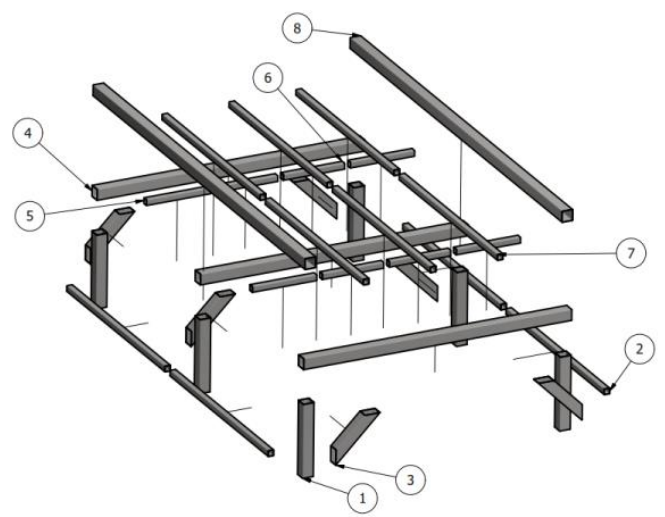

Gambar 5. Desain Perakitan Ulang Rangka CNC Plasma

Hasil analisis index perakitan desain ulang tertera pada Tabel 2 berikut.

Tabel 2. Analisis index perakitan desain rangka ulang

\begin{tabular}{clcc}
\hline & \multicolumn{1}{c}{ Deskripsi } & $\begin{array}{c}\text { Elemen } \\
\text { terhitung }\end{array}$ & $\begin{array}{c}\text { Naktu perakitan } \\
\text { (s) }\end{array}$ \\
\hline 1 & Kaki Rangka & 6 & 400 \\
2 & Penghubung bawah & 4 & 400 \\
3 & Penghubung sisi & 6 & 400 \\
4 & Tumpuan meja & 3 & 400 \\
5 & Tumpuan meja kecil A & 4 & 400 \\
6 & Tumpuan meja kecil B & 4 & 400 \\
7 & Tumpuan meja kecil C & 6 & 400 \\
8 & Gantry & 2 & 400 \\
\multicolumn{5}{c}{ TOTAL } & 35 & 3200 \\
\hline \multirow{4}{*}{ Index Perakitan : $\frac{35 \times 400}{3200}=4,375 \%$} \\
\hline \multicolumn{3}{c}{320}
\end{tabular}

Desain rangka ulang memiliki nilai index perakitan yang lebih tinggi yaitu 4,375\%. Gambar 6 menjelaskan 
bahwa setelah dilakukan analisis menggunakan metode DFMA, terdapat perbedaan dari konstruksi yang lebih praktis dengan nilai index desain yang lebih tinggi.
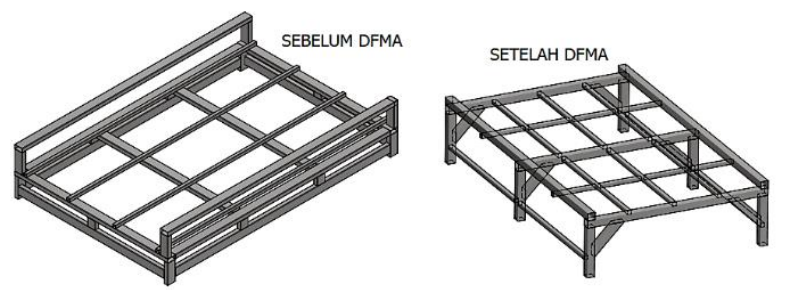

Gambar 6. Perbedaan Desain Rangka Setelah Analisis DFMA

B. Distribusi Beban dan Tegangan pada Rangka Mesin

Distribusi beban pada rangka merujuk kepada seluruh komponen yang ditopang mesin. Total beban yang ditanggung rangka tertera pada Tabel 3 berikut.

Tabel 3. Distribusi beban total pada rangka mesin

\begin{tabular}{clcc}
\hline No & \multicolumn{1}{c}{ Deskripsi } & Simbol & Beban \\
\hline 1 & Pelat / benda kerja & P1 & $2394.19 \mathrm{~N}$ \\
2 & pelat strip baja & P2 & $1485.76 \mathrm{~N}$ \\
3 & Air & P3 & $2349.435 \mathrm{~N}$ \\
4 & pelat meja & P4 & $659.721 \mathrm{~N}$ \\
\hline \multicolumn{2}{r}{ Ptotal } & & $6889.106 \mathrm{~N}$ \\
\hline
\end{tabular}

Guna menentukan besarnya gaya reaksi pada bantalan dapat digunakan model freebody diagram seperti pada Gambar 7.

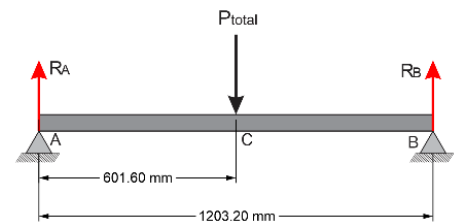

Gambar 7. Skema gaya pada rangka mesin

Dengan menguunakan persamaan (1) dengan prinsip statika struktur maka besarnya gaya reaksi adalah:

$$
\begin{aligned}
& \sum M_{A}=0 \\
& 0=- \text { Ptot } . A C+R B \cdot A B \\
& R B=\frac{\text { Ptot } . A C}{A B} \\
& =\frac{6889,106 N \cdot 601,6}{1203,2} \\
& =3444,553 N
\end{aligned}
$$

besarnya momen bending dari skema diatas, dengan menggunakan persamaan (2) adalah:

$$
\begin{aligned}
& M\left(x_{2}\right)=+R_{A} \cdot\left(x_{2}\right)-P_{1} \cdot\left(x_{2}-601 \cdot 6\right) \\
& M_{2}(606,1)=+3444,553 \cdot(601,6)-6889,106 \cdot(601,6-601,6) \\
& =2072243,08 N . m m
\end{aligned}
$$

Hasil perhitungan momen bending dapat dibuatkan diagram pada Gambar 8.

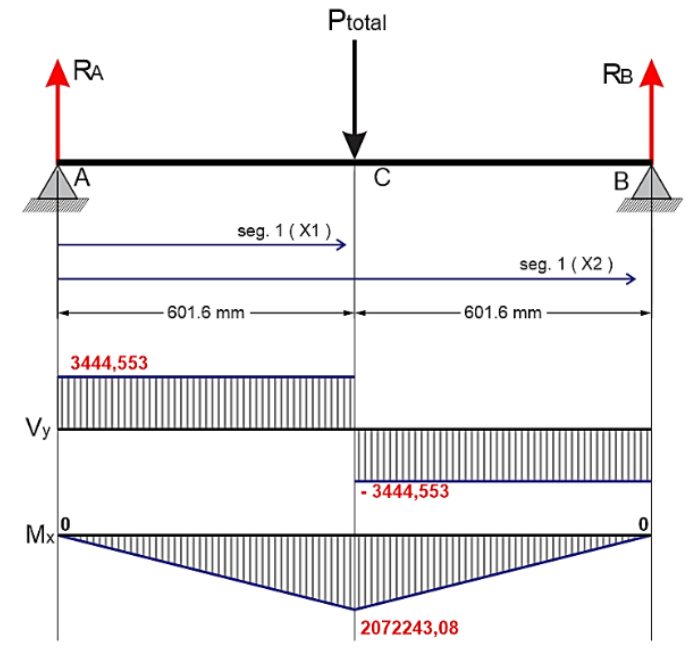

Gambar 8. Diagram Gaya Geser dan Momen Bending

Pada perancangan rangka mesin CNC plasma ini, dipilih menggunakan material JIS G 3466 Grade SKTR490. Material ini dipilih karena ketersidiannya yang mudah diperoleh di pasaran. Besarnya tegangan tarik maksimum $(\sigma \mathrm{u})=490 \mathrm{MPa}$, sementara tegangan izin $(\sigma \mathrm{i})=325 \mathrm{MPa}$ Bentuk profil yang dipilih adalah $75 \mathrm{~mm} \times 75 \mathrm{~mm} \times 2 \mathrm{~mm}$, dapat dilihat pada Gambar 9.

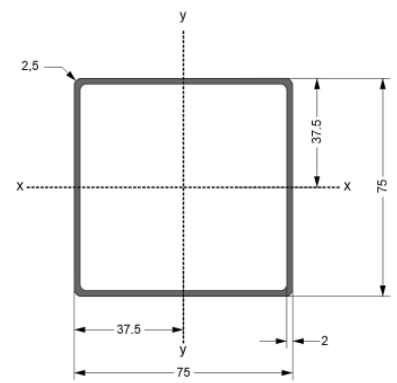

Gambar 9. Dimensi Detail Profil Baja

Tegangan yang terjadi pada rangka dapat ditentukan dengan persamaan (3).

$$
\sigma_{b}=\frac{2072243,08 \mathrm{~N} \cdot \mathrm{mm}}{15600 \mathrm{~mm}^{3}}=132.83 \mathrm{Mpa}
$$

Pemeriksaan harus dilakukan agar mengetahui tingkat keamanan konstruksi dengan menggunakan persamaan (4) dan (5)

$$
\begin{gathered}
\sigma_{i}=\frac{325 \mathrm{MPa}}{2}=162,5 \mathrm{Mpa} \\
\sigma_{i}>\sigma_{\text {total }}
\end{gathered}
$$

$162,5 \mathrm{MPa}>132,83 \mathrm{MPa}$

Hasil pemeriksaan menunjukan bahwa tegangan total yang terjadi pada konstruksi lebih kecil dari tegangan ijin material. dengan demikian perancangan konstruksi rangka memenuhi standar keamanan.

\section{Metode Elemen Hingga}

Untuk mngetahui tambahan hasil yang maksimal, digunakan bantuan perhitungan menggunakan software CAE (Computer Aided Engineering). Software CAE 
yang digunakan untuk simulasi adalah ANSYS. Gambar 10 berikut merupakan hasil deformasi yang diperoleh dari simulasi analisis struktur statis pada simulasi ANSYS;
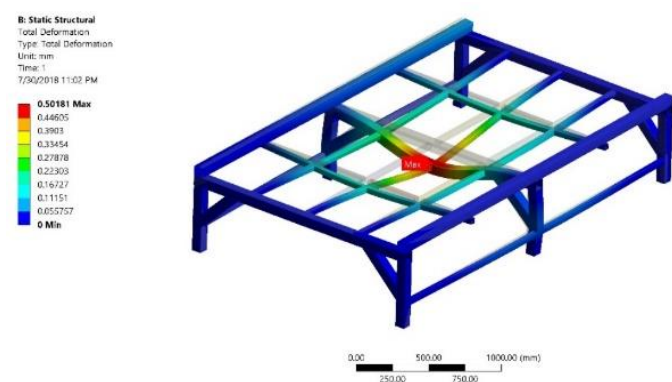

Gambar 10. Deformasi Total pada Rangka

Hasil analisis tegangan bending ditunjukkan pada gambar 11.
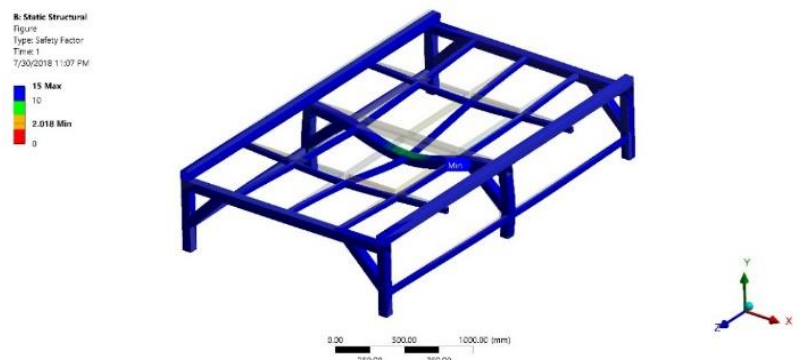

Gambar 11. Tegangan pada Rangka

Besarnya faktor keamanan dapat dilihat pada Gambar 12 berikut.

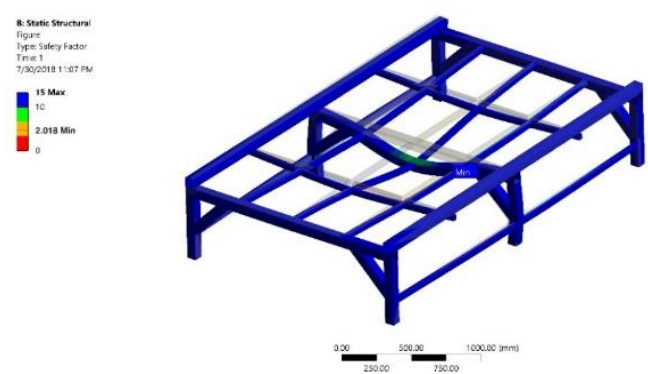

Gambar 12. Faktor Keamanan Rangka Mesin

Sebagai proses kalibrasi, dilakukan perbandingan antara hasil perhitungan manual dengan menggunakan persamaan yang berlaku dengan hasil analisis yang diperoleh dari simulai metode elemen hingga menggunakan software ANSYS. Perbandingan dari hasil perhitungan dan simulasi tersebut dijelaskan pada Tabel 4. berikut.

Tabel 4. Kalibrasi hasil analisis statika struktur rangka mesin

\begin{tabular}{clcc}
\hline No & Analisis & $\begin{array}{c}\text { Tegangan } \\
\text { maksimum }\end{array}$ & $\begin{array}{c}\text { Faktor } \\
\text { keamanan }\end{array}$ \\
\hline 1 & Perhitungan & $132,83 \mathrm{MPa}$ & 2 \\
2 & ANSYS & $132,045 \mathrm{MPa}$ & 2,018 \\
\hline & SELISIH & 0,785 & 0,018 \\
\hline
\end{tabular}

Dari hasil kalibrasi ditunjukkan bahwa nilai antara tegangan dan faktor keamanan mempunyai selisih yang sangat kecil. Oleh karena itu dapat disimpulkan bahwa desain rangka mesin telah memenuhi syarat standar untuk kemudian dapat dilakukan proses manufaktur.

\section{Proses Manufaktur Mesin CNC Plasma}

Seluru kegiatan dalam proses desain atau perancangan bertujuan sebagai dasar atau acuan untuk proses produksi agar ide atau gagasan rancangan menjadi kenyataan melalui proses manufaktur. Dalam kegiatan proses produksi mesin CNC plasma ini, lebih ditekankan kepada pemakaian biaya produksi yang seminimal mungkin. Oleh karena itu, proses produksi mesin dilakukan dengan teknik sederhana yang terdiri dari pemotongan, pengelasan, penyelesaian, serta perakitan mesin menjadi satu unit utuh.

Pengerjaan rangka mesin menjadi konsentrasi yang sangat diperhitungkan dalam proses manufaktur mesin ini. Pemotongan bahan baku berupa profil baja harus memiliki tingkat efisien yang tinggi. Oleh karena itu, dibuatkan bagan pembagian rangka seperti pada Gambar 13 berikut.

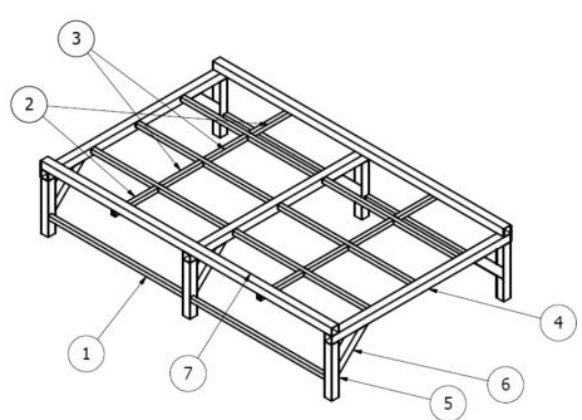

Gambar 13. Pembagian Elemen Rangka Mesin

Agar lebih menghemat pemakaian bahan baku, dibuatkan pola pemotongan profil baja yang tertera pada Gambar 14 berikut ini.

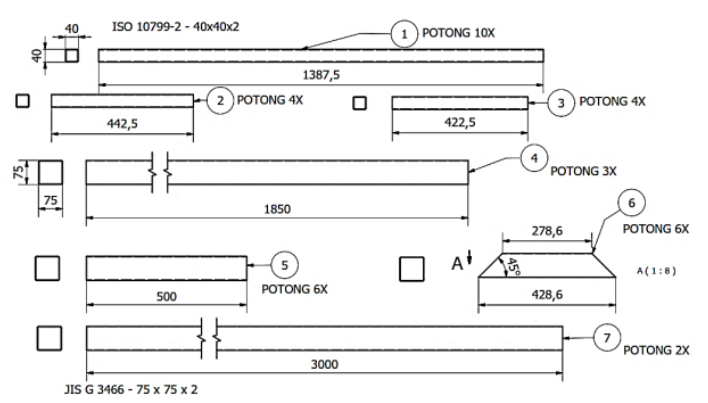

Gambar 14. Pembagian Elemen Rangka Mesin

Dari beberapa runtutan proses analisis mulai dari desain sampai dengan proses simulasi, proses manufaktur menghasilkan wujud nyata dari mesin CNC plasma. Gambar 15 menampilkan hasil dari proses manufaktur mesin CNC plasma. 


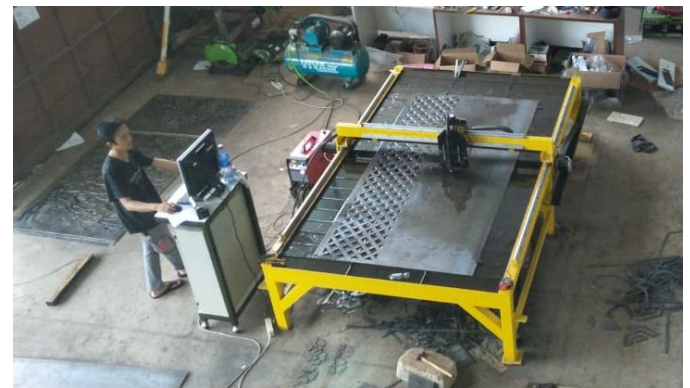

Gambar 15. Mesin CNC Plasma 3 Sumbu

Dalam pengujiannya, mesin CNC plasma difokuskan untuk langsung melakukan kegiatan produksi. Proses pemotongan logam dapat dilihat pada Gambar 16.

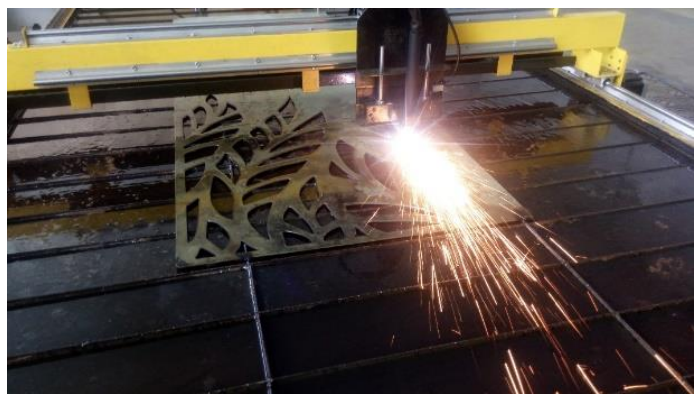

Gambar 16. Proses Pemotongan Logam dengan CNC Plasma

\section{KESIMPULAN}

Desain rangka dari proses perancangan ini telah mencapai standar keamanan untuk menampung beban total dari kapasitas pemotongan pelat baja setebal $10 \mathrm{~mm}$. Sistem mekanisme gerakan 3 sumbu yang dirancang juga memenuhi standar keamanan yang telah ditentukan dalam dunia teknik.

Desain rangka ulang memiliki nilai index perakitan yang lebih tinggi yaitu 4,375\%. Beban total rangka mesin, Ptotal $=6889,106 \mathrm{~N}$ Pada perancangan rangka mesin CNC plasma ini, dipilih menggunakan material JIS G 3466 Grade SKTR490. Material ini dipilih karena ketersidiannya yang mudah diperoleh di pasaran. Besarnya tegangan tarik maksimum $\left(\sigma_{\mathrm{u}}\right)=490 \mathrm{MPa}$, sementara tegangan izin $\left(\sigma_{\mathrm{i}}\right)=325 \mathrm{MPa}$ Bentuk profil yang dipilih adalah $75 \mathrm{~mm} \times 75 \mathrm{~mm} \times 2 \mathrm{~mm}$.

Dari segi kekuatan rangka mesin dapat dipastikan bahwa rancangan ini memenuhi standar. Dimana ketika dilakukan pemeriksaan yang diperoleh dari perbandingan tegangan ijin material dengan tegangan yang terjadi pada rangka yaitu $\sigma_{i}=325 \mathrm{MPa}>\sigma_{\text {total }}=132,83 \mathrm{MPa}$.

Selain perhitungan menggunakan persamaan yang berlaku, analisis juga dilakukan menggunakan metode elemen hingga menggunakan software ANSYS. Dari perbandingan hasil analisis manual dengan menggunakan software diperoleh perbandingan yang sangat kecil yaitu $0,785 \mathrm{MPa}$ untuk tegangan yang terjadi dan 0,018 untuk faktor keamanan. Hal ini mengindikasikan tingkat akurasi analisis yang baik melalui kedua metode tersebut.

Selanjutnya secara keseluruhan penelitian ini berhasil merancang sekaligus memproduksi mesin CNC plasma 3 sumbu. Proses manufaktur yang telah dilakukan menghasilkan mesin CNC plasma yang sudah dioperasikan dengan baik untuk proses pemotongan pelat baja.

\section{UCAPAN TERIMA KASIH}

Ucapan terima kasih diberikan kepada PT. Bangun Mesin Sejahtera atas dukungan penuh fasilitas ruang kerja selama mengerjakan penelitian ini.

Tidak lupa kepada Balai Teknologi Mesin Perkakas, Proses Produksi dan Otomasi (BT MEPPO) - BPPT yang terus memberikan dukungan terbaiknya dalam pengerjaan penelitian ini. Tentunya yang tidak bisa dilupakan adalah rasa terima kasih kepada seluruh pihak yang turut membantu dalam penyelesaian penelitian ini, namun tidak dapat disebutkan namanya satu persatu.

\section{REFERENSI}

[1] Asiabanpour, B., Vejandla, D. T., \& Jimenez, J., Optimising the automated plasma cutting process by design of experiments, Int. J. Rapid Manufacturing, Vol 1, 2009, pp. 19-40.

[2] Merriam-Webster's collegiate dictionary, Profil bisnis usaha mikro kecil dan menengah. Bank indonesia \& LPPI, 2015.

[3] Cahyono, E., \& Harianto, B. M., Rancang bangun meja mesin plasma cutting dengan gerak 3 axis $x, y, z$ menggunakan motor stepper berbasis Arduino, Institut Teknologi Sepuluh Nopember, 2017

[4] Yeong-min, N., Hyun-seok, L., \& Jong-kyu, P., A study on the improvement of the work tables CNC plasma cutting life, Journal of the Korean Society of Manufacturing Process Engineers, Vol 14, 2015, pp. 112124.

[5] Akhmad, A. A., Pemesinan nonkonvensional plasma arc cutting. Jurnal Rekayasa Mesin Fakultas Teknik Universitas Sriwijaya, 2009, 9, 51-56.

[6] Liza, F. P., Yao, C. B., \& Luces, J. L., Develompment of low-cost controller for the 3 axis computer numericallycontrolled (CNC) plasma cutting machine. Proceedings of the World Congress on Engineering and Computer Science, San Francisco: WCECS, Vol I, 2015, pp. 1-5.

[7] Boothroyd , G., Dewhurst, P., \& Knight, A. W, Product design for manufacture and assembly third edition, New York: CRC Press, 2011

[8] Patnaik, S. N., \& Hopkins, D. A, Strenghts of materials : a unified theory, Burlington: Elsevier, 2004

[9] Moaveni, S, Finite element analysis theory and application with ANSYS, Upper Saddle River, New Jersey: Prentice-Hall Inc, 1999

[10] Bosch Rexroth AG, Linear motion technology handbook, Schweinfurt: Ernst-Sachs-Straße, 2007

[11] Khurmi, R. S., \& Gupta, J. K, A text book of machine design, New Delhi: Eurasia Publishing House, 2005 